\title{
Smile Makeover
}

Smile is a curve that sets everything straight.

Esthetic dentistry today plays a major role in the practice of dentistry with ever-changing concepts on adhesion and the restorative materials used for smile designing and makeover. Hence, it is imperative for the clinicians to update themselves on the recent concepts of composite resins-the most commonly used esthetic restorative material.

Department of Conservative Dentistry and Endodontics of Sri Venkateswara Dental College \& Hospitals organized a one-day Continuing Dental Education program "Smile Makeover" in association with "Conservative Dentistry and Endodontics Association of Tamil Nadu" on July 20, 2016, at the college premises.

Prinicipal Dr Lodd Mahendra, Vice Principal Dr Yogesh PB, our speakers Dr Mohan, Secretary Indian Association of Conservative Dentistry and Endodontics (IACDE), and Dr Rajasekaran, Secretary Conservative Dentistry and Endodontics Association of Tamil Nadu (CEAT), and Dr Balagopal, Professor and Head, Department of Conservative Dentistry and Endodontics, Tagore Dental College, were a part of the inauguration ceremony. We were honored to have Dr Jaya Ranganathan, Professor and Head, Department of Conservative Dentistry and Endodontics, Priyadarshini Dental College.

Following a formal commencement by lighting the lamp, we proceeded with two lectures and a live demonstration.

Dr B Mohan is an accredited member of American Association of Cosmetic Dentistry. He presented a guest lecture on the topic "Smile Designing with Composites." He also presented a live demonstration on restoring fractured central incisor using composite resin.

Dr M Rajasekaran, professor from the Department of Conservative Dentistry and Endodontics of Ragas Dental College and Hospital delivered a lecture on "Ceramic Veneers".

About 200 delegates, postgraduates, and undergraduate students from various institutions and private practitioners took part in the Continuing Dental Education (CDE) program. The lectures and live demonstration were to give an insight to the various practical secrets of creating happy and lasting smiles. We were immensely pleased with the overwhelming response and reverberating success of the program.

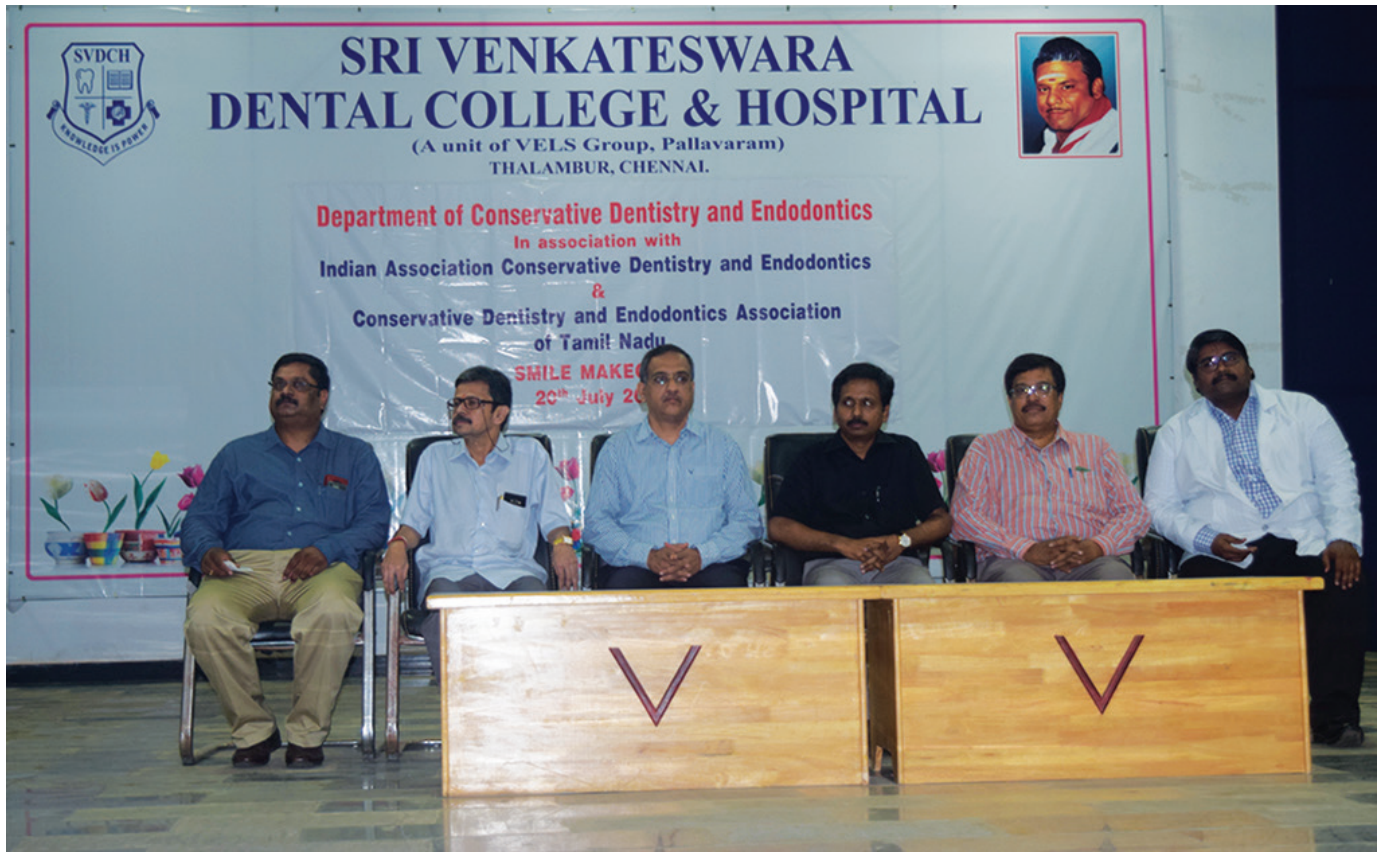

Manali Ramakrishnan Srinivasan Professor and Head Sri Venkateswara Dental College and Hospital Chennai, Tamil Nadu, India 